\title{
As Escolhas de Trabalhadores na Maturidade no Contexto de um Programa de Demissão Voluntária
}

\section{The Choices of Older Workers in the Context of a Voluntary Dismissal Program}

\author{
Lucia Barbosa de Oliveira \\ Doutora em Administração pelo Instituto Coppead de Administração da Universidade Federal \\ do Rio de Janeiro (Coppead-UFRJ) \\ Professora da Escola Brasileira de Administração Pública e de Empresas da Fundação Getulio \\ Vargas (FGV-EBAPE) \\ E-mail: lucia.oliveira@fgv.br \\ Carla Mendes de Oliveira \\ Mestre em Administração pelo IBMEC-RJ \\ Doutoranda no Instituto Superior de Ciências Sociais e Políticas da Universidade de Lisboa \\ E-mail: carlamendes1812@yahoo.com.br
}

Resumo: O envelhecimento da população brasileira vem ampliando o debate em torno da permanência e saída de trabalhadores na maturidade do mercado de trabalho. Evidências também apontam que empresas têm promovido o desligamento desses empregados, incluindo aqueles que prefeririam continuar trabalhando. Nesse sentido, a presente pesquisa teve por objetivo analisar os fatores que contribuíram para a decisão de aderir ou não ao programa de demissão voluntária (PDV) de uma grande empresa brasileira, voltado especificamente para empregados com mais de 55 anos e já aposentados pelo INSS. Participaram deste estudo qualitativo oito ex-empregados que aderiram ao PDV e oito empregados elegíveis ao programa que optaram por continuar na empresa. Os resultados mostraram que a decisão envolveu diversos fatores, incluindo saúde, situação financeira, questões familiares e o significado atribuído ao trabalho. Também foram identificadas perdas e ganhos associados à aposentadoria. Por fim, a partir das categorias centralidade do trabalho, dificuldade na tomada de decisão frente ao PDV e satisfação com a decisão, foram identificados seis grupos ou tipos ideais. Este trabalho contribui para preencher uma lacuna relativa à escassez de estudos nacionais sobre programas de desligamento voluntário. Além disso, espera-se que os resultados da pesquisa contribuam para a elaboração de políticas e práticas, por parte das organizações, que facilitem essa importante decisão.

Palavras-chave: Programa de Demissão Voluntária; Aposentadoria; Trabalhador na Maturidade; Significado do Trabalho.

\footnotetext{
Abstract: The aging of the Brazilian population has been broadening the debate around the exit and permanence of older workers from the labor market. Evidence also points out that companies have been promoting the dismissal of these employees, including those who would prefer to continue working. In this sense, the purpose of present research was to analyze the factors that contributed to the decision of whether to join the voluntary dismissal program (PDV) of a large Brazilian organization, targeted specifically at employees over 55 years-old who were already retired by the INSS. This qualitative study included eight former employees who joined the PDV and eight employees eligible to the program who chose to remain in the organization. The results showed that the decision was influenced by several factors, including health, financial situation, family issues and the meaning of work. Losses and gains associated with retirement were also identified. Lastly, based on the categories work centrality, indecision of whether to join the PDV, and satisfaction with the decision, six groups or ideal types were identified. This study contributes to fill a gap regarding the lack of empirical research on 
voluntary dismissal programs. In addition, the results of the research are expected to contribute to organizations' policies and practices that facilitate this important decision.

Keywords: Voluntary Dismissal Program; Retirement; Older Workers; Meaning of Work.

\section{INTRODUÇÃO}

Assim como em outros países do mundo, a população brasileira está envelhecendo, fruto da redução da taxa de natalidade e do aumento da expectativa de vida (CAMARANO, 2014). A estimativa é que o número de pessoas com 60 anos ou mais cresça vertiginosamente nas próximas décadas, passando de 20,9 milhões em 2010 para 42,1 milhões em 2030. Em 2060, estima-se que esse quantitativo suba para 73,5 milhões, equivalente a $32 \%$ da população total (BORGES; CAMPOS; CASTRO E SILVA, 2015; IBGE, 2018).

O crescimento da população idosa no país e questões envolvendo a reforma da previdência social têm suscitado o debate em torno da relação entre tempo de trabalho e aposentadoria. Se, por um lado, a maior expectativa de vida exigiria uma vida ocupacional mais longa, por outro lado as evidências apontam que trabalhadores na maturidade, definidos como aqueles com mais de 45 anos (WORLD HEALTH ORGANIZATION, 1993), vêm enfrentando crescentes dificuldades de permanência e reinserção no mercado de trabalho (LOTH; SILVEIRA, 2014; VANSTEENKISTE; DESCHACHT; SELS, 2015).

Nas organizações, tanto públicas quanto privadas, observa-se um crescimento das iniciativas de estímulo ao desligamento de empregados. Esses programas de demissão voluntária ou incentivada (PDVs ou PDIs) são adotados com o propósito de redimensionar o efetivo, renovar o quadro de pessoal ou simplesmente reduzir custos (ERNESTO; BELTRÃO; LOUREIRO, 1998). Em alguns casos, foca-se exclusivamente em empregados já aposentados pelo sistema nacional de seguridade social (OLIVEIRA-SILVA; VIEIRA; RIBEIRO, 2015).

Nesse sentido, o objetivo central desta pesquisa foi, a partir da perspectiva de trabalhadores na maturidade, analisar os fatores que influenciam a decisão de aderir a programas de demissão voluntária ou permanecer trabalhando na empresa. Também foram definidos os seguintes objetivos intermediários: (1) compreender o significado do trabalho na vida dos pesquisados, buscando comparar as perspectivas desses dois grupos; (2) analisar a realidade da aposentadoria na visão daqueles que optaram por aderir ao programa.

Para o alcance desses objetivos, foi desenvolvida uma pesquisa qualitativa junto a dois grupos distintos oriundos de uma mesma organização. O primeiro, chamado de "aposentados", é formado por oito pessoas que aderiram ao PDV e atualmente são ex-empregados da organização pesquisada. O segundo grupo, denominado "empregados", é formado por oito pessoas que optaram por não aderir ao programa e continuaram trabalhando na organização.

O presente estudo busca preencher uma lacuna na literatura sobre a tomada de decisão no contexto de programas de demissão voluntária, com destaque para a transição trabalhoaposentadoria (FRANÇA et al., 2013; OLIVEIRA-SILVA; VIEIRA; RIBEIRO, 2015; ZANELLI, 2012). Nesses programas, os empregados são obrigados a decidir respeitando uma data estipulada pela empresa, o que torna a situação peculiar e potencialmente capaz de influenciar a qualidade do processo decisório.

De uma perspectiva aplicada, a pesquisa é relevante para empresas que consideram adotar programas dessa natureza, visto que amplia o entendimento das vivências e percepções de potenciais participantes. Pelas mesmas razões, os resultados aqui apresentados podem ser úteis para profissionais que se encontram diante da decisão de aderir ou não a um PDV.

\section{REFERENCIAL TEÓRICO}

A fundamentação teórica para a pesquisa foi dividida em dois blocos. O primeiro trata do significado do trabalho e o segundo aborda a transição trabalho-aposentadoria, incluindo os 
motivadores relacionados à decisão pela aposentadoria e os possíveis caminhos que podem ser tomados por trabalhadores em idade de se aposentar.

\subsection{Trabalho e seus significados}

A literatura sobre trabalho e seus significados aponta duas visões antagônicas. A primeira refere-se ao trabalho como algo sacrificante, penoso e punitivo, e está relacionada à própria origem da palavra - tripalium -, que significa instrumento de tortura. A segunda visão, mais positiva, remete à possibilidade de desenvolvimento das habilidades humanas e atingimento de objetivos (ALBORNOZ, 2004; MORIN, 2001; NEVES et al., 2018). Codo (2006) também reconhece o caráter dual do trabalho, abrangendo alienação, por um lado, e construção do homem por si próprio, de outro.

Duas linhas de pesquisa são consideradas pioneiras no entendimento do significado do trabalho. A primeira foi desenvolvida por Hackman and Oldman (1976), segundo os quais um trabalho teria significado na medida em que mobilizasse diferentes habilidades, gerasse resultados tangíveis - com começo, meio e fim - e fosse percebido como relevante para outras pessoas. Na década de 1980, um grupo de pesquisadores - denominado Meaning of Working International Research Team (MOW) - realizou um amplo estudo sobre o significado do trabalho, tendo identificado três aspectos que auxiliam nessa compreensão: centralidade do trabalho, normas sociais e objetivos e resultados valorizados no trabalho (MOW, 1987).

A centralidade pode ser interpretada como o grau de importância do trabalho para uma pessoa em determinado momento. Essa importância advém não apenas do tempo gasto com as atividades laborativas, mas dos ganhos financeiros e psicológicos advindos do trabalho (BIANCHI, 2018). Quanto mais importante for considerado o trabalho, mais central ele será para o indivíduo. As normas sociais dizem respeito aos direitos e deveres percebidos pelo indivíduo em relação à sociedade e à organização em que trabalha. Em outras palavras, referemse às convenções sociais que influenciam atitudes e comportamentos do trabalhador (MOW, 1987; LEMOS; CAVAZOTTE; SOUZA, 2017). Por fim, os objetivos e resultados valorizados envolvem a motivação e satisfação do indivíduo perante o trabalho. Ou seja, trata dos motivos pelos quais a pessoa trabalha e o que torna algumas posições mais atrativas do que outras (BASTOS; PINHO; COSTA, 1995; MOW, 1987).

Outro importante modelo a respeito do significado do trabalho foi desenvolvido por Morin (2001), considerada uma referência nos estudos sobre o tema no Brasil (NEVES et al., 2018; SPINELLI-DE-SÁ; LEMOS, 2017). Segundo a autora, seis fatores dariam sentido a um trabalho: (1) ser realizado eficientemente, trazendo retornos positivos; (2) ser prazeroso ou intrinsicamente satisfatório; (3) envolver boas relações sociais, seja com a equipe interna ou com pessoas externas à organização; (4) ser moralmente aceitável ou socialmente responsável; (5) garantir o sustento e a autonomia do trabalhador; (6) manter a pessoa ocupada, dando sentido ao seu dia a dia.

Outras abordagens foram desenvolvidas com o intuito de explicar o significado do trabalho. A partir de ampla revisão da literatura, Rosso, Dekas e Wrzesniewski (2010) propuseram um modelo baseado em duas dimensões - agência/comunhão e self/outro - que, combinadas, gerariam quatro mecanismos de significado, chamados de individuação (agência e self), contribuição (agência e outro), conexão com o self (comunhão e self) e unificação (comunhão e outro). Lips-Wiersma e Wright (2012), por sua vez, desenvolveram uma escala composta por quatro fatores, denominados unidade com os outros, serviço aos outros, expressando o próprio potencial e desenvolvendo o eu interior. Segundo os autores, o significado do trabalho adviria de tensões internas entre o eu e o outro e entre o ser e o fazer.

No presente estudo, adotamos o conceito de centralidade do trabalho (MOW, 1987) e o enfoque proposto por Wrzesniewski et al. (1997), que contempla três possíveis orientações acerca do trabalho: emprego, carreira e vocação. Os indivíduos orientados para o emprego veem 
suas atividades laborativas apenas como fonte de recursos financeiros que serão utilizados em outras áreas da vida. $\mathrm{O}$ trabalho está associado ao sustento e o interesse está nas recompensas monetárias e bens materiais que o trabalho pode proporcionar. A orientação para a carreira envolve autoestima e satisfação. Para esses indivíduos, o trabalho não significa apenas ganhar dinheiro, mas implica no alcance de diferentes objetivos e reconhecimento pessoal. Por fim, indivíduos orientados para a vocação veem o trabalho como fonte de sentido. Em outras palavras, o trabalho é percebido como um fim sem si e como fonte de realização pessoal. Essas pessoas, portanto, estariam mais propensas a situar o trabalho no centro de suas vidas e podem ter mais dificuldade para se aposentar.

\subsection{A transição trabalho-aposentadoria}

Considerando-se a importância e as diferentes funções do trabalho na vida das pessoas, a aposentadoria tende a ser um fenômeno complexo, que envolve tanto um processo psicológico quanto uma mudança objetiva de fase da vida (WANG; SHI, 2014; WANG; WANBERG, 2017). Também é possível identificar diferentes definições para aposentadoria na literatura, incluindo a ausência de qualquer envolvimento em atividades laborais, o desligamento do principal empregador, o recebimento de pensão após determinados anos de trabalho, independentemente de envolvimento com atividades laborais ou, ainda, a autoavaliação desta condição (WANG; SHI, 2014).

Nesse sentido, Beehr (2014) destaca que a aposentadoria é mais do que uma escolha dicotômica entre continuar trabalhando e se desligar integralmente de atividades laborais. A autora acrescenta que o processo é também complexo porque usualmente vem acompanhado de queda de rendimentos, além de menos tempo de dedicação ao trabalho e menor envolvimento psicológico com o mesmo.

$\mathrm{Na}$ psicologia, são identificadas três diferentes perspectivas sobre o tema: a da aposentadoria como uma decisão, como um processo de ajuste ou como uma etapa no desenvolvimento da carreira (WANG; SHI, 2014; WANG; WANBERG, 2017). A perspectiva da tomada de decisão tem como foco o processo decisório e seus motivadores, enquanto a perspectiva do ajuste reconhece a aposentadoria como um processo de transição que ocorre ao longo de determinado período, e não como um ponto único no tempo. Feldman e Beehr (2011) acrescentam que esse processo envolve três diferentes etapas, que são a preparação, a transição trabalho-aposentadoria e o ajuste à vida de aposentado. Por fim, a aposentadoria pode ainda representar uma outra etapa na carreira de um indivíduo, associada a uma nova forma de envolvimento com o trabalho (WANG; WANBERG, 2017). No presente estudo, o foco reside nos fatores que influenciam o processo de tomada de decisão e no ajuste posterior.

O indivíduo com idade para se aposentar e elegível a um programa de desligamento incentivado tem como opções permanecer trabalhando na mesma organização, sair da organização e buscar uma ocupação diferente ou viver a aposentadoria definitiva. Num estudo com trabalhadores na maturidade, Boveda e Metz (2016) identificaram quatro trajetórias possíveis - continuar trabalhando, sair definitivamente do mercado de trabalho, obter um emprego-ponte ou começar uma nova carreira (encore career). Segundo os autores, essa escolha é influenciada pelo gênero, condição financeira, saúde e situação conjugal, entre outros fatores.

Duarte e Melo-Silva (2009, p. 46) destacam que a população mais velha "tem buscado se manter produtiva e empregada", por razões que vão além da necessidade financeira. Optar pela aposentadoria e sair de um emprego pode representar uma grande perda, principalmente quando o papel profissional ocupa o centro da vida (POST; SCHNEER; REITMAN, 2013). Ao mesmo tempo, a opção por permanecer pode ser resultado de incertezas e dúvidas, dentre elas a falta de um planejamento de vida após a aposentadoria (KERRY, 2018). 
Para aqueles que desejam reduzir seu envolvimento com o trabalho, uma possibilidade é o emprego-ponte, definido como um trabalho remunerado - tipicamente mais flexível desempenhado no período compreendido entre a aposentadoria e a saída definitiva do mercado de trabalho (AVERHART, 2012; KIM; FELDMAN, 2000; SULLIVAN; ARISS, 2019). Kim e Feldman (2000) também destacam a importância do trabalho voluntário e de atividades de lazer, entendidas como estratégias de desaceleração e/ou adaptação à aposentadoria.

Diversos pesquisadores têm se dedicado à compreensão dos fatores que influenciam o processo de tomada de decisão em relação à aposentadoria, incluindo apego à carreira e ao trabalho, seguridade social, situação financeira, saúde e realidade familiar e matrimonial, além dos custos e benefícios percebidos em relação à vida de aposentado (BOVEDA; METZ, 2016; FRANÇA, 2008; SULLIVAN; ARISS, 2019; WANG; SHI, 2014).

No que tange à realidade familiar, a situação do cônjuge e o relacionamento do casal são fatores que influenciam a decisão (FIGUEIRA et al., 2017). Gielen (2007) aponta que as pessoas ficam menos propensas à aposentadoria se o cônjuge ainda estiver trabalhando. Segundo Szinovacz (2003), apesar das mulheres estarem cada vez mais presentes no mercado de trabalho, os homens ainda são vistos como os principais provedores e, por isso, é comum que a mulher se aposente antes do marido ou que a aposentadoria ocorra para o casal de maneira simultânea. Relacionamentos desgastados influenciam a não aposentadoria, pois os indivíduos preferem passar mais tempo trabalhando a conviver com o cônjuge. Além disso, a existência de filhos dependentes também representa um fator para a postergação da aposentadoria (SZINOVACZ, 2003; WANG; SHI, 2014). Com relação à saúde, o "estar bem" aumenta a probabilidade de se continuar trabalhando (FRANÇA; MENEZES, 2012; GIELEN, 2007). Por fim, Post, Schneer e Reitman (2013) verificaram que a centralidade do trabalho também está relacionada com a decisão de postergar a aposentadoria.

Shultz, Morton e Weckerle (1998) estudaram a influência de fatores positivos (pull) e negativos (push) na opção pela aposentadoria. Os autores ressaltam que fatores negativos têm impacto maior no processo de adaptação e incluem problemas de saúde, problemas financeiros e insatisfação com o trabalho atual. Os fatores pull incluem a busca por mais tempo livre para o lazer, o trabalho voluntário, a família, a possibilidade de viajar mais e poder controlar o próprio tempo. Cabe destacar que o mesmo fator pode ser considerado como positivo ou negativo por diferentes indivíduos, dependendo do contexto. A aposentadoria incentivada, por exemplo, pode ser encarada das duas maneiras (HANKS, 1990). Ou seja, pode ser pull para aqueles que já estavam pensando em se aposentar e pode ter sido push em função do incentivo financeiro atrelado a tais programas.

Guedes, Calado e Vieira (1998) estudaram as motivações de saída no contexto de um PDV e identificaram a falta de perspectiva na carreira, a insatisfação com a empresa, a vontade de deixar o papel de empregado e a verba indenizatória como fatores relevantes para a decisão de sair. Gielen (2007), por outro lado, observa que flexibilidade de horário no trabalho colabora para a postergação da aposentadoria e a permanência dos mais velhos em seus empregos.

Outro tema de estudos diz respeito às consequências da aposentadoria. Szinovacz (2003) afirma que a experiência da aposentadoria depende das características do trabalho, do contexto e da trajetória de carreira de cada indivíduo. França e Soares (2009) identificaram nove fatores relacionados à aposentadoria, sendo cinco positivos e quatro negativos. Dos cinco fatores percebidos como positivos, a questão do tempo está presente em três deles: ter mais tempo para os relacionamentos, para o lazer e para os investimentos, além de conquistar liberdade do trabalho e começar uma nova etapa na vida. A valorização do tempo livre e da flexibilidade de horários também foi observada por Bitencourt et al. (2011). Com relação às perdas, também apontadas por Silva e Helal (2017), destacam-se as relacionadas a fatores tangíveis (ambiente), emocionais (reconhecimento e satisfação), sociais (relacionamentos com colegas da empresa) e financeiros (remuneração menor). A prevalência de dimensões positivas ou negativas tende a 
depender de aspectos individuais, familiares, econômicos e ambientais (FRANÇA; SOARES, 2009).

Debetir e Monteiro (1999) observam que, além da perda das referências e do contato com os colegas de trabalho, o aposentado pode se deparar com redução de status e possíveis perdas financeiras. Além disso, a visão negativa sobre o processo de envelhecimento, os preconceitos contra os idosos e as perdas relacionadas à idade são fatores que prejudicam o desenvolvimento de uma aposentadoria saudável, na medida em que podem camuflar os possíveis ganhos nessa etapa da vida. A visão da aposentadoria como voluntária ou compulsória também afeta o bem-estar dos aposentados. Segundo Shultz, Morton e Weckerle (1998), ser percebida como voluntária promove a satisfação do indivíduo com vida, além de resultar em melhores condições de saúde física e mental. Por outro lado, para que as perdas da aposentadoria sejam minimizadas e os ganhos reforçados, destaca-se a importância de planejamento anterior e o estabelecimento de novas atividades e prioridades após a aposentadoria (FRANÇA; SOARES, 2009; KERRY, 2018; TOPA et al., 2009).

\section{MÉTODO}

Para o alcance dos objetivos propostos, optou-se pelo método qualitativo e exploratório, considerado apropriado para o entendimento de percepções e sentimentos (FLICK, 2009). O estudo foi conduzido junto a um grupo de empregados e ex-empregados de uma grande empresa brasileira de economia mista. Foram entrevistados 16 participantes, sendo oito que não aderiram ao programa e continuam trabalhando na empresa (grupo dos empregados) e oito que aderiram ao programa e, portanto, deixaram a empresa (grupo dos aposentados). Para participar da pesquisa, o entrevistado deveria estar no grupo de elegíveis ao PDV, ou seja, ter idade igual ou superior a 55 anos e estar aposentado pelo INSS. Respeitado esse quesito, os entrevistados foram escolhidos pela acessibilidade.

A coleta de dados envolveu entrevistas pessoais, conduzidas com o apoio de dois roteiros semiestruturados, um para cada grupo pesquisado. Os encontros ocorreram nas instalações da empresa, na casa dos participantes ou em estabelecimentos comerciais. As entrevistas tiveram duração entre 45 e 90 minutos, totalizando aproximadamente 900 minutos. Todas foram gravadas, com a devida autorização dos participantes, e posteriormente transcritas.

O método de análise e interpretação das falas dos participantes foi o da análise de conteúdo. Inicialmente, as transcrições foram lidas e analisadas individualmente, em seguida por grupo e posteriormente comparadas, a fim de se identificar semelhanças e diferenças entre aqueles que aderiram ao programa e os que permaneceram na empresa. As categorias de análise foram definidas a priori, com base na literatura e nos objetivos da pesquisa, e incluíram: significado do trabalho, satisfação com a empresa/trabalho, decisão em relação ao PDV, atividades extratrabalho, saúde, situação financeira, vida pessoal/familiar, planejamento para a aposentadoria e vida após a aposentadoria (somente para o grupo dos aposentados).

Dos 16 participantes, havia cinco homens e 11 mulheres, com idades entre 56 e 75 anos e tempo de empresa entre 5 e 39 anos - ver Quadro 1. No que tange a situação familiar, 11 eram casados, 4 divorciados e uma solteira. Além disso, 14 possuíam um ou mais filhos e apenas uma morava sozinha. Na organização pesquisada, três ocupavam funções de nível superior e 14 exerciam funções técnicas, que exigem apenas o ensino médio. 
Quadro 1 - Perfil dos Entrevistados

\begin{tabular}{|c|c|c|c|c|c|c|c|}
\hline $\mathbf{N}^{\circ}$ & Gênero & Idade & Função & $\begin{array}{l}\text { Tempo de } \\
\text { empresa } \\
\text { (anos) }\end{array}$ & $\begin{array}{c}\text { Estado } \\
\text { Civil }\end{array}$ & Reside com & $\begin{array}{c}\text { Idades dos } \\
\text { filhos } \\
\text { (anos) }\end{array}$ \\
\hline \multicolumn{8}{|c|}{ Empregados } \\
\hline E1 & Masculino & 72 & Nível superior & 9 & Casado & Esposa & 48 \\
\hline E2 & Feminino & 65 & Nível superior & 16 & Casada & Esposo & 43 e 46 \\
\hline E3 & Feminino & 59 & Técnica & 9 & Casada & Esposo & 30 e 33 \\
\hline E4 & Masculino & 60 & Técnica & 38 & Casado & Esposa & 25 \\
\hline E5 & Feminino & 60 & Técnica & 5 & Divorciada & Filho & 24 e 32 \\
\hline E6 & Feminino & 59 & Nível superior & 5 & Divorciada & Filho & 34 e 35 \\
\hline E7 & Feminino & 58 & Técnica & 30 & Casada & Marido e filhas & 30 e 42 \\
\hline E8 & Masculino & 75 & Técnica & 5 & Casado & Esposa, filha e 2 netos & 39 \\
\hline \multicolumn{8}{|c|}{ Aposentados } \\
\hline $\mathrm{A} 1$ & Feminino & 56 & Técnica & 35 & Divorciada & Filhos & 20,24 e 26 \\
\hline A2 & Feminino & 57 & Técnica & 34 & Casada & Esposo e filho & 19 \\
\hline A3 & Feminino & 61 & Técnica & 34 & Solteira & Sobrinho & Sem filhos \\
\hline A4 & Feminino & 60 & Técnica & 39 & Casada & Esposo & Sem filhos \\
\hline A5 & Masculino & 65 & Técnica & 37 & Casado & Esposa & 33 \\
\hline A6 & Feminino & 63 & Técnica & 28 & Casada & Esposo & 37 \\
\hline A7 & Feminino & 66 & Técnica & 9 & Divorciada & Sozinha & 43 \\
\hline A8 & Masculino & 63 & Técnica & 38 & Casado & Esposa e filhos & 26 e 29 \\
\hline
\end{tabular}

\section{ANÁLISE E DISCUSSÃO DOS RESULTADOS}

A análise dos dados foi estruturada em quatro seções. A primeira trata do significado do trabalho na vida dos entrevistados. Na segunda seção são discutidos os principais fatores que influenciaram a decisão de sair ou de permanecer na empresa. Em seguida, discute-se a realidade dos oito aposentados que aderiram ao PDV. Por fim, a quarta seção é dedicada à tipologia desenvolvida a partir das características dos participantes e categorias estudadas.

\subsection{Significado do trabalho na vida dos entrevistados}

Quando perguntados sobre o significado do trabalho, vários participantes do grupo dos empregados demonstraram alta centralidade (MOW, 1987). Apesar de alguns terem citado a questão do trabalho como forma de sustento e segurança, diversos outros fatores foram incluídos, como satisfação pessoal e bom ambiente de trabalho (MORIN, 2001).

Eu sempre faço uma comparação do trabalho com o casamento. Eu me sinto casada com o trabalho. (E2)

O trabalho pra mim é tudo. (E3)

O trabalho representa a nossa própria vida. (E4)

Eu preciso trabalhar, preciso. Preciso para mim, não pelo dinheiro. (E5)

No grupo dos aposentados, houve destaque à função do trabalho como meio de sobrevivência financeira e recompensas monetárias, mas também como um meio de aprendizado e satisfação intrínseca (MORIN, 2001).

Graças ao meu trabalho, eu consegui o que eu tenho hoje, ajudar os meus pais, criar uma família. (A2)

Muita coisa que aprendi lá, hoje eu trago para a minha vida particular porque, como você sabe, eu sou advogada [...]. Atualmente eu tenho 
saudades, não tenho vontade de voltar, mas eu fico relembrando aqueles momentos que eu passei lá. (Al)

O trabalho representou pra mim um modo de vida. [...] você se sente valorizada, você está produzindo, [...] é uma forma de você ter conhecimento, sabedoria. (A3)

Apesar de terem optado pela adesão ao PDV, três aposentados demonstraram alta centralidade do trabalho (A5, A7, A8). A8 possui uma condição especial e diferente dos demais, pois tem sérios problemas de saúde que requerem tratamento diário e, nesse sentido, sua aposentadoria parece ter sido forçada e não uma opção.

Eu acho que a pessoa sem trabalho é um infeliz. (A5)

Ai meu Deus do céu, sinto muita falta hoje. Eu acho que trabalho é tudo, né?

[...]. Ah, se tivesse oportunidade, com certeza eu voltaria. (A7)

Fazendo uma comparação entre os dois grupos, é possível verificar que o trabalho é relevante para ambos. Com relação às funções do trabalho apontadas na literatura, para os empregados, as funções mais destacadas foram ter uma ocupação, satisfação intrínseca, se sentir útil, relacionamento interpessoal e sustento. Para os aposentados, o significado do trabalho é semelhante, porém a questão financeira foi mais realçada (MORIN, 2001; MOW, 1987).

A partir das análises sobre o significado do trabalho para empregados e aposentados, fizemos uma associação com as orientações propostas por Wrzesniewski et al. (1997), apresentadas no Quadro 2. Dos oito empregados, cinco se mostraram orientados para vocação e três para carreira. No grupo dos aposentados, dois dos que se mostraram orientados para vocação foram exatamente os que se arrependeram da decisão de sair da empresa (A5 e A7). Além disso, a orientação para o emprego apareceu somente no grupo dos aposentados, sinalizando que essa orientação pode ser um fator que pesa na decisão pela aposentadoria. Perceber o trabalho simplesmente como fonte de renda pode ser uma condição que facilita o desapego das atividades laborativas e, consequentemente, a decisão pela aposentadoria. Por outro lado, os indivíduos que encaram o trabalho como carreira ou como vocação teriam mais dificuldades nesse sentido.

Quadro 2 - Orientações em relação ao trabalho

\begin{tabular}{|c|c|c|}
\hline Orientação predominante & Grupo dos aposentados & Grupo dos empregados \\
\hline Emprego & A2, A4, A6 & - \\
\hline Carreira & A1, A3 & E5, E6, E8 \\
\hline Vocação & A5, A7, A8 & E1, E2, E3, E4, E7 \\
\hline
\end{tabular}

\subsection{Motivadores de adesão ou permanência}

Nesta seção são analisados os fatores que influenciaram a decisão dos entrevistados perante o PDV. São identificados e discutidos os motivos pelos quais os participantes da pesquisa optaram por sair ou permanecer na empresa.

\subsubsection{Expectativa de realização do $\mathrm{PDV}$}

Três aposentados contaram que o PDV já estava sendo aguardado há alguns anos, o que pode ter facilitado a decisão de aderir ao programa. Os demais também pareciam decididos a 
se aposentar e mostraram reações positivas quando o programa foi divulgado. No grupo dos empregados, esse aspecto não foi mencionado.

Há muitos anos nós estávamos aguardando esse PDV. (A5)

Olha, esse PDV eu já vinha aguardando há uns quatro anos. [...]. Comecei a me preparar psicologicamente. (A6)

\subsubsection{Saúde}

Segundo a literatura, a saúde é um fator relevante para a tomada de decisão pela aposentadoria (AVERHART, 2012; BEEHR, 2014; GIELEN, 2007; FRANÇA; MENEZES, 2012; SZINOVACZ, 2003). No grupo dos aposentados, dois afirmaram que saíram da empresa por problemas de saúde e dois mostraram preocupação em aproveitar a vida enquanto ainda podem. Ou seja, tanto problemas de saúde quanto o desejo de se aposentar ainda com saúde parecem estimular a decisão.

Eu não estava conseguindo curtir a minha vida, entendeu? Porque eu já estava [...] trabalhando fora do meu horário, [...] isso aí estava prejudicando a minha saúde. [...] a minha decisão foi mais por saúde mesmo. (Al)

Você sente... organicamente, fisicamente, você sente que está chegando a sua hora de parar. E se você não parar para aproveitar, colher os frutos do seu trabalho, vai chegar uma hora que você vai estar doente, que você vai estar numa cama, e não aproveitou nada. Só trabalhou a vida toda. [...]. (A6)

Por não conseguir conciliar o trabalho com sua rotina de tratamentos, o aposentado A8 se viu obrigado a aderir ao PDV. Nesse caso, a saúde debilitada pode ser entendida como um fator push, ou sejam que "empurra" a pessoa para a aposentadoria (SHULTZ; MORTON; WECKERLE, 1998).

No grupo dos empregados, metade apresenta boas condições de saúde e metade afirmou ter problemas. Desta forma, não foi possível relacionar questões relativas à saúde com a decisão de permanecer.

Minha saúde está danada. [...]. Eu sinto que esse horário pesadão está prejudicando a minha saúde. [...]. Eu gostaria que alguém na [nome da empresa], principalmente tendo em vista que agora as pessoas estão vivendo muito mais tempo [...], nem que dessem um salário menor, entrasse num acordo coletivo, sei lá o que, proporcional às horas trabalhadas, [...]. Muita gente se tivesse uma possibilidade dessas não parava de trabalhar. (E2)

A saúde é [...] uma droga. De repente, [...] pressão alta, [...] dor no estômago, mas tudo é o trabalho. (E7)

\subsubsection{Relações familiares}

Dois motivadores considerados relevantes para a aposentadoria são a situação do cônjuge e filhos dependentes (AVERHART, 2012; GIELEN, 2007; KIM; FELDMAN, 2000; SZINOVACZ, 2003; WANG; WANBERG, 2017). Com relação à situação do cônjuge, as mulheres tendem a se aposentar antes ou junto com os maridos, devido ao papel de provedor que o homem ainda representa na sociedade (GIELEN, 2007; SZINOVACZ, 2003).

No grupo dos empregados, seis possuem cônjuge, mas apenas três deles trabalham. O empregado E1 é o único homem que tem uma esposa trabalhando e esse parece ser um dos motivos pelos quais ele diz não parar de trabalhar.

A minha mulher [...] está o dia inteiro no consultório. Eu só pararia de trabalhar se a minha mulher parasse de trabalhar. (E1) 
No grupo dos aposentados, cinco possuem cônjuge e apenas dois deles trabalham. Esses que trabalham são homens, o que corrobora as evidências de que a mulher tende a se aposentar antes ou concomitantemente com seus esposos (GIELEN, 2007; SZINOVACZ, 2003).

De vez em quando a gente viaja porque o meu marido tem uma pousada no interior da Bahia, junto com o irmão. (A4)

Com relação à existência de filhos dependentes, Szinovacz (2003) defende que as pessoas nessa situação estão menos propensas à aposentadoria. Nesta pesquisa, essa tendência não foi verificada, uma vez que sete empregados e cinco aposentados sustentam filhos ou ajudam financeiramente outras pessoas da família. Ou seja, para os participantes desta pesquisa, a decisão de sair ou permanecer não parece ter sido influenciada por esse fator.

\subsubsection{Atividades extratrabalho}

Com exceção de E2, os empregados não se dedicam a atividades fora do trabalho. Alguns fazem atividades físicas, mas não demonstram desenvolver outros interesses pessoais. Nesse cenário, o trabalho torna-se o ponto focal na vida dessas pessoas e a aposentadoria pode ser mais difícil.

Dos aposentados, duas começaram a desenvolver novos interesses enquanto ainda estavam trabalhando e outra tinha interesse por artesanato, mas não conseguia se dedicar em função da jornada de trabalho. Esses fatores podem ter influenciado a adesão ao PDV e também a satisfação com a decisão (KIM; FELDMAN, 2000; POST; SCHNEER; REITMAN, 2013; SZINOVACZ, 2003). Por outro lado, outros cinco optaram por sair mesmo não tendo outros interesses fora do trabalho.

\subsubsection{Verbas recebidas no PDV e finanças pessoais}

O recebimento das verbas advindas de um programa de demissão voluntária pode contribuir para a decisão de sair da empresa (GUEDES; CALADO; VIEIRA, 1998). Três aposentados contam que, sem o PDV, não teriam se aposentado. Um deles diz sentir saudades e outros dois afirmaram que voltariam a trabalhar na empresa, evidenciando ter se arrependido da decisão.

Com esse dinheiro, deu pra fazer aquilo que eu fiz. [...] não teria como fazer a obra dos meus pais. (A3)

Com certeza não estaria aposentado. [...]. Eu gosto de trabalhar. [...] trabalhar pra mim é a minha vida, era tudo. [...], mas aí eu botei na balança: "Se eu for agora, tem o PDV". (A5)

Se não saísse (o PDV), eu estaria aqui até hoje, com certeza. Comprar a casa que era o meu sonho mesmo, acompanhar a obra lá da reforma. (A7)

Enquanto esses aposentados analisaram as verbas como atrativas, quatro empregados (E1, E3, E5, E8) não aderiram ao PDV justamente por não terem visto vantagem nos valores que iriam receber do programa. Cabe ressaltar que esses quatro empregados tinham relativamente pouco tempo de trabalho na empresa. Desta forma, podemos concluir que as verbas rescisórias influenciam positivamente a decisão pela aposentadoria apenas nos casos de empregados com mais anos de empresa, tendo em vista que as verbas costumam ser proporcionais ao tempo de trabalho.

Primeiro, [...] eu não vou sair daqui para procurar outro emprego, [...] porque eu não tenho mais idade para estar trabalhando em outro lugar. Segundo, [...] teria que ser uma coisa mais compensatória. (E1) 
Aí eu fui fazer conta, essas coisas. Aí eu falei: "Não, muito baixo. Não vou não. Vou ficar mais um pouco". (E3)

As finanças pessoais também são consideradas relevantes na decisão frente à aposentadoria (FRANÇA; SOARES, 2009; SZINOVACZ, 2003). O fato de possuir casa própria e uma vida financeira considerada estável parece ter favorecido a adesão ao PDV por quatro aposentados (A1, A2, A4, A5).

Eu tenho umas reservas aí. Então, se eu quiser viajar, dá pra fazer. [...] Eu já tenho casa própria [...]. Então assim, eu não estou mais tão dependente da empresa. (Al)

Você tem que ter aquela certeza que você não paga mais apartamento, [...] ter a vida organizadinha, um pé de meia feito para alguma coisa, e aí vai tranquilo. (A4)

\subsubsection{Liberdade de horário}

A vontade de ter mais liberdade e mais tempo livre é considerada relevante para a decisão pela aposentadoria (FRANÇA; SOARES, 2009; BITENCOURT et al., 2011) e também foi observada nesta pesquisa.

Eu hoje faço o meu horário, você entendeu? (Al)

Eu senti que estava na hora de eu começar a viver minha vida, sem precisar me preocupar com o tempo. (A6)

Um pouco mais de tempo pra eu me desenvolver no meu novo trabalho porque eu já era advogada. (A3)

Me dedicar mais um pouco ao artesanato que eu gosto de fazer [...] não tinha tempo, só final de semana. (A7)

Nesse sentido, cumpre apontar que vários participantes (tanto aposentados quanto empregados) destacaram como um ponto negativo a pouca flexibilidade de horário existente na empresa.

A coisa que mais me preocupa no momento, o que mais me desgasta é o horário, por causa da idade e dos problemas de saúde que eu tenho. Eu não quero parar de trabalhar, mas eu sinto que está ficando muito difícil conciliar esse horário tão pesado com os problemas que eu tenho. (E2)

o que eu menos gostava, eu vou te dizer. É exatamente aquela prisão, o tempo que a minha vida ficava ali presa. Isso foi uma coisa que me incomodou a vida toda. (A6)

\subsubsection{Falta de perspectiva na carreira}

A falta de perspectivas na carreira, apontada como importante por Guedes, Calado e Vieira (1998), foi observada no caso de dois aposentados (A2 e A3). O pouco estímulo à capacitação também foi mencionado por alguns dos entrevistados que ocupavam cargos técnicos.

Essa política de me tirarem, me mandarem pra um serviço e mandarem pro outro, eu fui sacrificada [...]. Há um favoritismo aqui dentro. (A3)

Eu vi que dentro da empresa, [...] por já me encontrar no último nível do meu cargo, eu não tinha muita expectativa de promoção. (A2) 


\title{
4.3 A vida após a aposentadoria
}

Cinco aposentados (A1, A2, A3, A4, A6) afirmaram que a decisão perante o PDV foi boa e que estão satisfeitos nessa nova fase da vida.

\begin{abstract}
Muito satisfeita. Em momento algum eu me arrependi de ter me aposentado, em momento algum eu lamentei nada. Eu sou muito grata a tudo que me aconteceu. (A2)

Para mim, foi uma alegria. Porque se eu ia sair só com a aposentadoria, receber esse dinheiro, a minha decisão [...] não tinha outra. Eu tenho que ir embora porque eu não rasgo dinheiro. (A4)
\end{abstract}

Dois entrevistados (A5 e A7), por outro lado, disseram que sentem muita falta da empresa e demonstraram arrependimento. Em ambos os casos, fica evidente nos relatos a pressão que sentiram para se aposentar em função das verbas e/ou prazos envolvidos.

Eu ainda pretendia ficar mais uns dois, três anos, mas aconteceu. [...]. Muitas saudades, dói muito. Evito falar porque às vezes falta a voz. (A5)

Precipitada não foi porque [...] eu não teria a oportunidade que eu tive de realizar meu sonho (comprar a casa). Mas se tivesse outro (PDV) mais para frente, né? Se a gente tivesse certeza que ia ter, até teria ficado um pouco mais. Ai meu Deus do céu, sinto muita falta hoje. Eu acho que trabalho é tudo, né? (A7)

Quando perguntados sobre o que mais sentem falta na empresa, todos os aposentados incluíram os colegas de trabalho nas respostas, evidenciando a importância das relações humanas que se desenvolvem no trabalho (MORIN, 2001). A perda dos vínculos sociais foi um aspecto também identificado por Silva e Helal (2017).

Eu sinto falta dos colegas, daquele convívio. (A3)

Com relação às rotinas atuais, duas aposentadas adotaram o emprego-ponte (KIM; FELDMAN, 2000), uma como síndica e outra como advogada, e parecem satisfeitas por seu envolvimento em atividades laborais. Cabe destacar que ambas se envolveram nessas atividades antes de sair da empresa, o que pode ter facilitado a decisão.

Eu sou o tipo da síndica que eu gosto de ver tudo, eu acompanho o serviço das pessoas. [...]. O dia a dia é agitado de segunda a sexta. [...]. Ou seja, eu continuo nessa agitação. Então, isso aí para mim por um lado está sendo ótimo porque eu estou tendo uma atividade, eu não estou parada. (Al)

Primeiro lugar, eu gosto muito da advocacia. Eu gosto, eu trabalho por prazer. E decidi trabalhar pelo seguinte: Como é que eu vou ficar parada? Eu acho que se eu fosse ficar parada eu ia ficar tediosa. (A3)

Os demais estão se dedicando a hobbies, como escrever, fazer artesanato e dançar. Como apontado por Debert (1999), a aposentadoria tem sido vista como uma possibilidade de dedicação a atividades que geram satisfação pessoal. A liberdade de horário desfrutada na aposentadoria foi um fator destacado por quatro entrevistados deste grupo (FRANÇA; SOARES, 2009).

A minha vida está maravilhosa. Estou tendo mais tempo de conversar com meu filho, com meu marido, de organizar minha casa [...]. Eu voltei a escrever, que eu adoro escrever. Então, a aposentadoria me fez muito bem, é como se eu tivesse sido uma pessoa e agora sou outra. (A2) 
Agora não tem tanto horário para acordar, [...]. Eu estou tratando da saúde, faço fisioterapia, faço caminhada, cuido da vida e cuido da casa. [...]. Agora eu não quero ter obrigação [...]. Eu vou fazendo o que me der vontade. (A4)

No que tange o fator saúde, quatro aposentados (A1, A2, A7 e A8) perceberam uma melhora depois que se aposentaram, inclusive A8, que se aposentou forçadamente por conta de sua saúde, um resultado que encontra respaldo na literatura (BEEHR, 2014).

Você saindo, você tem mais tempo de você ir a médico, fazer um tratamento decente. (Al)

Acho que eu melhorei (risos). Eu melhorei bastante porque você tem mais atividade ao ar livre, você caminha, você tem as horas de sono adequadas, alimentação, você tem oportunidade de se cuidar melhor. (A2)

Com relação à vida financeira, cinco aposentados sentiram a redução dos proventos e outros três (A2, A4 e A6), não. No entanto, mesmo entre aqueles que afirmaram estar vivendo com uma renda menor, esse fator não emergiu com relevante no processo de adaptação à aposentadoria. Segundo Wang e Shi (2014), o bem-estar financeiro na aposentadoria está relacionado a uma carreira relativamente estável, como é o caso dos participantes. Com exceção de A7, todos trabalharam por 28 anos ou mais na empresa.

Antes de me aposentar eu já sabia, a gente tem que ter noção [...] a gente tem que viver de acordo com que a gente ganha. [...]. Claro que muitos itens são poupados dos nossos proventos (férias, PLR, etc.), mas em compensação, muitos gastos que eu tinha eu deixei de ter. Então, eu não me senti abalada financeiramente. (A2)

Pra te falar a verdade, eu não senti tanta diferença como muita gente falou [...]. A única coisa que você sente, isso é uma coisa óbvia, que você deixa de ter aqueles dinheiros extras (férias, PLR). [...] Aprendi com meu filho e com meu marido a me organizar financeiramente. (A6)

O lado financeiro muda muito. Hoje, eu não tenho PL, não tenho férias. (A8)

A partir das entrevistas com os aposentados e conforme apresentado no Quadro 3, foi possível identificar tanto perdas quanto ganhos associados à aposentadoria, conforme aponta a literatura sobre o tema (FRANÇA, 2008; FRANÇA; SOARES, 2009; SZINOVACZ, 2003; WANG; WANBERG, 2017). Apenas três aposentadas (A2, A4 e A6) não perceberam nenhuma perda com a aposentadoria, sendo que uma delas ressalta a importância do planejamento nessa fase da vida: "a pior coisa que pode acontecer para o aposentado é ele não ter planejamento" (A2). Nesse sentido, é possível considerar, também em linha com a literatura, que o planejamento representa um aspecto crucial para a satisfação com a vida de aposentado (FRANÇA; SOARES, 2009; KERRY, 2018; PRINCIPI et al., 2020; TOPA et al., 2009).

\section{Quadro 3 - Ganhos e perdas com a aposentadoria}

\begin{tabular}{|l|l|}
\hline \multicolumn{2}{|c|}{ Ganhos percebidos } \\
\hline Liberdade de horário, não ter compromisso & $\mathrm{A} 1, \mathrm{~A} 2, \mathrm{~A} 4, \mathrm{~A} 5, \mathrm{~A} 6, \mathrm{~A} 7$ \\
\hline Tempo para se cuidar & $\mathrm{A} 3$ \\
\hline Saúde melhor & $\mathrm{A} 1, \mathrm{~A} 2, \mathrm{~A} 7, \mathrm{~A} 8$ \\
\hline \multicolumn{2}{|c|}{ Perdas percebidas } \\
\hline Ociosidade & $\mathrm{A} 1$ \\
\hline Não ter rotina & $\mathrm{A} 3$ \\
\hline Contato com o trabalho e convívio com os colegas & $\mathrm{A} 5, \mathrm{~A} 8$ \\
\hline Perdas financeiras (renda menor) & $\mathrm{A} 1, \mathrm{~A} 3, \mathrm{~A} 5, \mathrm{~A} 7, \mathrm{~A} 8$ \\
\hline Envelhecimento & $\mathrm{A} 7$ \\
\hline
\end{tabular}




\subsection{Tipos ideais}

A partir das entrevistas e num esforço de síntese dos resultados, foi possível identificar seis grupos ou tipos ideais, construídos a partir da centralidade e/ou orientação em relação ao trabalho (MOW, 1987; WRZESNIEWSKI et al., 1997), da percepção de dificuldade em relação à decisão de aderir ou não ao PDV e das vivências e sentimentos após a decisão, conforme apresentado no Quadro 4.

Quadro 4 - Tipos Ideais

\begin{tabular}{|c|c|c|c|c|}
\hline $\begin{array}{c}\text { Grau de } \\
\text { satisfação }\end{array}$ & \multicolumn{2}{|c|}{ Empregados } & \multicolumn{2}{c|}{ Aposentados } \\
\hline Satisfeitos & Apegados & E2, E3, E4, E5, E8 & Adaptados & A1, A2, A3, A4, A6 \\
\hline \multirow{2}{*}{ Neutros } & Indecisos & E6, E7 & - & A5, A7 \\
\hline \multirow{2}{*}{ Insatisfeitos } & Arrependido & E1 & Arrependidos & A8 \\
\cline { 2 - 5 } & - & - & Forçado & \\
\hline
\end{tabular}

Apegados: No grupo dos apegados, encontram-se cinco empregados que optaram por não aderir ao PDV em função de um grande apego ao trabalho e à empresa, tanto de uma perspectiva emocional quanto financeira. As características compartilhadas por este grupo são alta centralidade do trabalho, facilidade na tomada de decisão de não aderir ao PDV e satisfação com decisão tomada.

Enquanto eu tiver saúde, eu quero trabalhar. (E2)

Indecisos: As principais características deste grupo de empregados são alta centralidade do trabalho e dificuldade na tomada de decisão frente ao PDV, aspectos que em seu conjunto afetaram sua satisfação com o processo como um todo. As duas pessoas que se enquadram nesse perfil (E6, E7) chegaram a se inscrever no programa, mas cancelaram quando souberam que seu desligamento seria imediato. Ambas demonstraram não estar preparadas para a aposentadoria, tanto pela importância do trabalho em suas vidas quanto pelo tempo para tomada de decisão, considerado muito curto.

Resolvi me inscrever, custou muito, mas resolvi. Tive os meus filhos dando o maior apoio. Aí bateu uma coisa aqui dentro. [...] tomei a decisão de cancelar a minha inscrição e não sair. (E6)

Empregado Arrependido: neste grupo há apenas um empregado (E1), também com alta centralidade do trabalho e dificuldade na tomada de decisão, mas com grande arrependimento e insatisfação com a decisão tomada. Sua situação é bastante peculiar, pois o arrependimento se deveu a problemas de saúde enfrentados após o término do prazo de adesão. A doença e o arrependimento evidenciam sua insatisfação. Se tivesse aderido ao PDV, provavelmente teria as mesmas características do aposentado A8, detalhado mais adiante.

Por volta de outubro, [...] confessei um arrependimento [...] porque eu achava que ia morrer, [...] eu tenho um problema grave de pulmão. [...]. Se sair um novo PDV, eu saio. (E1)

Adaptados: as principais características desse grupo são sua tranquilidade na decisão pela adesão ao PDV e boa adaptação à vida de aposentado. A baixa centralidade do trabalho e 
a visão do trabalho como emprego ou como carreira (percebida como chegando ao fim) também são características desse grupo.

Foi facílima. [...] eu já atingi uma idade que daqui a pouco as doenças vão começar a aparecer. Eu quero aproveitar minha vida antes que essas doenças apareçam. (Al)

Para mim foi fácil, porque como eu te falei, eu já estava com cerca de trinta $e$ oito anos de trabalho [...] eu já tinha um plano de aposentadoria. Em momento algum eu me arrependi de ter me aposentado. (A2)

Alguns (A1, A4 e A6) já haviam decidido se aposentar e a chegada do PDV serviu como um incentivo e facilitador do processo. A1 começou a se envolver em atividades de gestão predial antes da aposentadoria, enquanto A4 e A6 queriam mais liberdade de tempo, apesar de gostarem da empresa e das atividades que desenvolviam. Os outros dois membros desse grupo (A2 e A3) não se planejaram com antecedência, mas sua insatisfação com a empresa serviu de estímulo adicional à aposentadoria, que acabou se refletindo positivamente em suas vidas.

Eu aposentada poderia exercer a minha profissão à vontade, primeiro. Segundo, dinheiro. Eu tenho umas reservas, então se eu quiser viajar dá para fazer. E terceiro, essa questão da profissão de síndica, que foi uma coisa que me interessou, tanto que eu fiz os cursos e vou continuar fazendo. (Al)

Eu sempre disse assim: "Com 60 anos, por que eu vou ficar trabalhando? Se eu comecei com 20, se eu trabalhei por 40, se eu tenho a minha vida organizada, se eu tenho tudo estruturado financeiramente, me organizei para isso, o marido já está aposentado". (A4)

Isso foi uma coisa que sempre me incomodou a vida toda, o tempo que você fica dentro de uma empresa [...]. A vida acontecendo lá fora e eu querendo estar lá fora vivendo e não conseguia. [...]. Eu senti que estava na hora de começar a viver minha vida, sem precisar me preocupar com o tempo. E poder ter a liberdade de sair, de aproveitar, de viajar, de fazer os meus cursos de artesanato. (A6)

Aposentados Arrependidos: as características que definem este grupo são a alta centralidade do trabalho, a dificuldade na tomada de decisão em relação ao PDV, além da insatisfação com a vida após a aposentadoria. As aposentadas A5 e A7 afirmam que sentem falta do trabalho e que não teriam saído sem as verbas do PDV, indicando que o fator mais importante para a decisão foi financeiro. Cabe frisar também que, enquanto estiveram na empresa, não desenvolveram outras atividades fora dela.

Eu ainda pretendia ficar mais uns dois, três anos, mas aconteceu. [...]. Muitas saudades, dói muito. Evito falar porque às vezes falta a voz. (A5)

Ai meu Deus do céu, sinto muita falta hoje. [...]. Ah, se tivesse oportunidade, com certeza eu voltaria. (A7)

Forçado: o último grupo tem como característica a adesão ao PDV por motivos negativos (push), indicando que não houve planejamento prévio e que a decisão foi difícil, visto que forçada. O aposentado A8, único deste grupo, tem um grave problema de saúde e se viu obrigado a aderir ao programa para poder realizar os tratamentos médicos necessários: "Se eu pudesse, voltaria a trabalhar. [...]. Eu decidi (sair) por causa da saúde”. 


\section{CONSIDERAÇÕES FINAIS}

Esta pesquisa teve por objetivo analisar os fatores que contribuíram para a decisão de aderir ou não ao programa de demissão voluntária (PDV). Dos fatores que influenciaram a decisão, pode-se destacar a expectativa de realização do programa, aguardada há alguns anos, além de questões de saúde, financeiras e familiares.

A insatisfação com o trabalho e com a empresa também parece ter contribuído para a adesão ao programa, ponto apontado por Wang e Shi (2014), segundo os quais as características do último trabalho - incluindo níveis de estresse e carga de trabalho - influenciam a decisão em relação à aposentadoria. No presente estudo, a falta de perspectiva de carreira e a pouca flexibilidade de horário foram os fatores destacados.

Com relação a este último ponto, ambos os grupos mencionaram que a pouca flexibilidade de horário prejudica a saúde e o desenvolvimento de outras atividades além do trabalho. Nesse sentido, é importante que as empresas estudem formas de ampliar a flexibilidade de horário para que os atuais empregados, especialmente os que já se encontram mais próximos da aposentadoria, possam desenvolver novos interesses e conciliar vida pessoal e profissional. As pessoas que se envolvem em outras atividades fora do trabalho tendem a estar mais preparadas para a vida na aposentadoria (SZINOVACZ, 2003; WANG; SHI, 2014).

$\mathrm{O}$ recebimento das verbas indenizatórias foi outro fator que influenciou a decisão. A partir dos relatos dos aposentados arrependidos, é possível considerar que aqueles que saem exclusivamente por causa do dinheiro têm maiores chances de arrependimento. Esse resultado sinaliza duas implicações práticas. Em primeiro lugar, é importante que os trabalhadores tenham consciência de que a decisão não deve ser tomada com base apenas em questões financeiras, sendo necessária a devida preparação (DEBETIR; MONTEIRO, 1999; FRANÇA; SOARES, 2009). As organizações que promovem tais programas, por sua vez, podem contribuir nesse sentido, destacando aos seus empregados que a opção pelo desligamento deve envolver um planejamento prévio de longo prazo e não deve ser motivada unicamente pelo retorno a curto prazo.

A pressão de tempo envolvida nos PDVs parece ter contribuído para decisões posteriormente percebidas como equivocadas (aposentados arrependidos). Como implicação prática desse resultado, sugere-se às organizações que venham a conduzir programas de demissão voluntária que deem tempo hábil para que os empregados possam refletir sobre a decisão que precisam tomar e planejar a transição. Ações de orientação aos empregados também podem contribuir nesse sentido.

Com relação aos objetivos secundários do estudo, procuramos analisar e comparar o significado do trabalho na vida dos grupos de empregados e aposentados. Não observamos diferenças significativas em relação à centralidade do trabalho, o que pode ser explicado pelo fato de que todos escolheram trabalhar numa grande empresa e nela permaneceram por muitos anos. Por outro lado, foram encontradas diferenças em relação às orientações propostas por Wrzesniewski et al. (1997). A orientação para o emprego só emergiu no grupo dos aposentados, o que sugere que esta orientação pode contribuir para a opção pela aposentadoria.

Também foi avaliada a vivência da aposentadoria daqueles que aderiram ao programa e, nesse sentido, foi possível identificar que sua satisfação parece ser positivamente influenciada por um planejamento prévio e pelo envolvimento em atividades extratrabalho, em linha com a literatura (FRANÇA; SOARES, 2009; KERRY, 2018; PRINCIPI et al., 2020; TOPA et al., 2009). Por outro lado, a pressão de tempo e a decisão tomada predominantemente em função das verbas indenizatórias do PDV parecem ter contribuído para gerar frustrações e arrependimento.

Esta pesquisa possui algumas limitações que cabem ser mencionadas. Em primeiro lugar, adotamos as literaturas sobre significado do trabalho e sobre a transição trabalhoaposentadoria como lentes teóricas para a análise das entrevistas, deixando de lado outras 
perspectivas que poderiam ter agregado ao entendimento do fenômeno. Além disso, ficamos restritas às peculiaridades deste grupo de participantes, envolvidos em um mesmo programa de demissão incentivada e num mesmo contexto histórico-social.

Como sugestão para estudos futuros, esperamos que os tipos ideais aqui apresentados estimulem o desenvolvimento de pesquisas que testem a aderência dos mesmos a outras organizações que tenham implementado programas de demissão voluntária e outros contextos, permitindo o avanço teórico neste campo. Também pode ser interessante a condução de estudos com profissionais - em idade para se aposentar - submetidos a jornadas flexíveis ou com carga inferior a 40 horas, a fim de relacionar a intenção de aposentadoria com os fatores tempo dedicado às atividades laborais, centralidade do trabalho e desgaste físico. Por fim, propomos a continuidade do debate sobre a longevidade e o mundo do trabalho, tão importante no cenário atual.

\section{REFERÊNCIAS}

ALBORNOZ, S. O que é trabalho. São Paulo: Brasiliense, 2004.

AVERHART, V. Ageism in the workplace: examining the influence of age conceptualization on the advancement opportunities of older workers. FIU Electronic Theses and Dissertations, paper 585, 2012.

BASTOS, A. V. B.; PINHO, A. P. M.; COSTA, C. A. Significado do trabalho: um estudo entre trabalhadores inseridos em organizações formais. RAE - Revista de Administração de Empresas, v. 35, n. 6, p. 20-29, 1995.

BEEHR, T. A. To retire or not to retire: That is not the question. Journal of Organizational Behavior, v. 35, n. 8, p. 1093-1108, 2014.

BIANCHI, E. M. P. G. Meaning of work for managers in the Brazilian contemporary business context. RAM - Revista de Administração Mackenzie, v. 19, n. 5, p. 1-29, 2018.

BITENCOURT, B. M. et al. Para além do tempo de emprego: o sentido do trabalho no processo de aposentadoria. Revista de Ciências da Administração, v. 13, n. 31, p. 30-57, 2011.

BORGES, G. M.; CAMPOS, M. B.; CASTRO E SILVA, L. G. Transição da estrutura etária no Brasil: oportunidades e desafios para a sociedade nas próximas décadas. In: ERVATTI, L. R.; BORGES, G. M.; JARDIM, A. P. (Orgs.). Mudança demográfica no Brasil no início do Século XXI. Rio de Janeiro: IBGE, 2015.

BOVEDA, I.; METZ, A. J. Predicting end-of-career transitions for baby boomers nearing retirement age. Career Development Quarterly, v. 64, n. 2, p. 153-168, 2016.

CAMARANO, A. A. Introdução. In: Camarano, A. A. (Org.). Novo regime demográfico: uma nova relação entre população e desenvolvimento? Rio de Janeiro: IPEA, 2014.

CODO, W. Por uma psicologia do trabalho: ensaios recolhidos. São Paulo: Casa do Psicólogo, 2006.

DEBETIR, E.; MONTEIRO, L. A. S. Qualidade de vida e preparação para a aposentadoria na Universidade Federal de Santa Catarina. In: Encontro Nacional da ANPAD, 1999. Foz do Iguaçu. Anais... Rio de Janeiro: Anpad, 1999.

DEBERT, G. G. A reinvenção da velhice: socialização e processos de reprivatização do envelhecimento. São Paulo: EDUSP, 1999. 
DUARTE, C. V.; MELO-SILVA, L. L. Expectativas diante da aposentadoria: um estudo de acompanhamento em momento de transição. Revista Brasileira de Orientação Profissional, v. 10, n. 1, 2009.

ERNESTO, R.; BELTRÃO, V.; LOUREIRO, M. R. Reforma da burocracia pública e federalismo no Brasil: a experiência do programa de demissão voluntária nos governos estaduais. RAP - Revista de Administração Pública, v. 32, n. 6, 113-144, 1998.

FELDMAN, D. C.; BEEHR, T. A. A three-phase model of retirement decision making. American Psychologist, v. 66, n. 3, p. 193-203, 2011.

FIGUEIRA, D. A. M. et al. A tomada de decisão da aposentadoria influenciada pelas relações familiares e laborais. Revista Brasileira de Geriatria e Gerontologia, v. 20, n. 2, p. 207-215, 2017.

FLICK, U. Introdução à Pesquisa Qualitativa. 3. ed. Porto Alegre: Artmed, 2009.

FRANÇA, L. H. O desafio da aposentadoria: o exemplo dos executivos do Brasil e da Nova Zelândia. Rio de Janeiro: Rocco, 2008.

FRANÇA, L. H. et al. Aposentar-se ou continuar trabalhando? O que influencia essa decisão? Psicologia, Ciência e Profissão, v. 33, n. 3, p. 548-563, 2013.

FRANÇA, L. H.; MENEZES, G. S. Motivadores da decisão da aposentadoria por servidores públicos federais. Psicologia: Organizações e Trabalho, v. 12, n. 3, 2012.

FRANÇA, L. H.; SOARES, D. H. P. Preparação para a aposentadoria como parte da educação ao longo da vida. Psicologia: Ciência e Profissão, v. 29, n. 4, p. 738-751, 2009.

GIELEN, A. C. Working hours flexibility and older workers labor supply. IZA Discussion Paper Series, n. 2946, 2007.

GUEDES, V. A.; CALADO, S. M. R.; VIEIRA, M. M. F. Programa de desligamento voluntário: um estudo sobre os fatores determinantes da adesão entre ex-funcionários de instituição financeira governamental. In: Encontro Nacional da ANPAD, 1998. Anais... Rio de Janeiro: Anpad, 1998.

HACKMAN, J. R.; OLDHAM, G. R. Motivation through the design of work: test of a theory. Organizational Behavior and Human Performance, v. 16, n. 2, p. 250-279, 1976.

HANKS, R. S. The impact of early retirement incentives on retirees and their families. Journal of Family Issues, v. 11, n. 4, p. 424-437, 1990.

IBGE - INSTITUTO BRASILEIRO DE GEOGRAFIA E ESTATÍSTICA. Brasil: Projeção da população por sexo e idade - 2010/2060. Rio de Janeiro: IBGE, 2018. Disponível em: $<$ https://www.ibge.gov.br/estatisticas/sociais/populacao/9109-projecao-da-

populacao.html?=\&t=downloads $>$. Acesso em 12/11/2019.

KERRY, M. J. Psychological antecedents of retirement planning: A systematic review. Frontiers in Psychology, v. 9, p. 1-17, 2018.

KIM, S.; FELDMAN, D. Working in retirement: The antecedents of bridge employment and its consequences for quality of life in retirement. Academy of Management Journal, v. 43, n. 6, p. 1195-1210, 2000.

LEMOS, A. H. C.; CAVAZOTTE, F. S. C. N.; SOUZA, D. O. S. De empregado a empresário: mudanças no sentido do trabalho para empreendedores. Revista Pensamento Contemporâneo em Administração, v. 11, n. 5, p. 103-115, 2017. 
LIPS-WIERSMA, M.; WRIGHT, S. Measuring the meaning of meaningful work: Development and validation of the Comprehensive Meaningful Work Scale (CMWS). Group and Organization Management, v. 37, n. 5, p. 655-685, 2012.

LOTH, G. B.; SILVEIRA, N. Etarismo nas organizações: um estudo dos estereótipos em trabalhadores envelhecentes. Revista de Ciências da Administração, v. 16, n. 39, p. 65-82, 2014.

MORIN, E. M. Os sentidos do trabalho. RAE - Revista de Administração de Empresas, v. 41, no 3, p. 8-19. 2001.

MOW (THE MEANING OF WORKING INTERNATIONAL RESEARCH TEAM). The meaning of working. London: Academic Press, 1987.

NEVES, D. R. et al. Sentido e significado do trabalho: uma análise dos artigos publicados em periódicos associados à Scientific Periodicals Electronic Library. Cadernos EBAPE.BR, v. 16, n. 2, p. 318-330, 2018.

OLIVEIRA-SILVA, L.; VIEIRA, J. A.; RIBEIRO, A. C. B. Para além do fim do arco-íris: motivações e consequências da adesão ao plano de demissão voluntária. ReCaPe - Revista Carreiras \& Pessoas, v. 5, n. 2, p. 270-281, 2015.

POST, C.; SCHNEER, J. A.; REITMAN, F. Pathways to retirement: A career stage analysis of retirement age expectations. Human Relations, v. 66, n. 1, p. 87-112, 2013.

PRINCIPI, A. et al. What happens to retirement plans, and does this affect retirement satisfaction? International Journal of Aging and Human Development, v. 90, n. 2, p. 152$175,2020$.

ROSSO, B. D.; DEKAS, K. H.; WRZESNIEWSKI, A. On the meaning of work: A theoretical integration and review. Research in Organizational Behavior, v. 30, p. 91-127, 2010.

SHULTZ, K. S.; MORTON, K. R.; WECKERLE, J. R. The influence of push and pull factors on voluntary and involuntary early retirees' retirement decision and adjustment. Journal of Vocational Behavior, v. 53, p. 45-57, 1998.

SILVA, A. C. C.; HELAL, D. H. Compreendendo a aposentadoria: Um estudo de caso em uma instituição pública do Estado de Pernambuco. REGE - Revista de Gestão, v. 24, n. 4, p. 316324, 2017.

SPINELLI-DE-SÁ, J. G.; LEMOS, A. H. C. Sentido do trabalho: Análise da produção científica brasileira. Revista ADM.MADE, v. 21, n. 3, p. 21-39, 2017.

SULLIVAN, S. E.; ARISS, A. A. Employment after retirement: A review and framework for future research. Journal of Management, v. 45, n. 1, p. 262-284, 2019.

SZINOVACZ, M. E. Contexts and pathways: Retirement as institution, process, and experience. In: ADAMS, G. A; BEEHR, T. A. (Eds.). Retirement: Reasons, process, and results. New York: Springer Publishing Company, 2003.

TOPA, G. et al. Antecedents and consequences of retirement planning and decision-making: A meta-analysis and model. Journal of Vocational Behavior, v. 75, n. 1, p. 38-55, 2009.

VANSTEENKISTE, S.; DESCHACHT, N.; SELS, L. Why are unemployed aged fifty and over less likely to find a job? A decomposition analysis. Journal of Vocational Behavior, v. 90, p. $55-65,2015$.

WANG, M.; SHI, J. Psychological research on retirement. Annual Review of Psychology, v. 65, n. 1, p. 209-233, 2014. 
WANG, M.; WANBERG, C. R. 100 years of applied psychology research on individual careers: From career management to retirement. Journal of Applied Psychology, v. 102, n. 3, p. 546-563, 2017.

WORLD HEALTH ORGANIZATION. Aging and working capacity. Geneva: World Health Organization, 1993.

WRZESNIEWSKI, A. et al. Jobs, careers, and callings: People's relations to their work. Journal of Research in Personality, v. 31, n. 1, p. 21-33, mar. 1997.

ZANELLI, J. C. Processos psicossociais, bem-estar e estresse na aposentadoria. Revista Psicologia, v. 12, n. 3, p. 329-340, 2012. 